
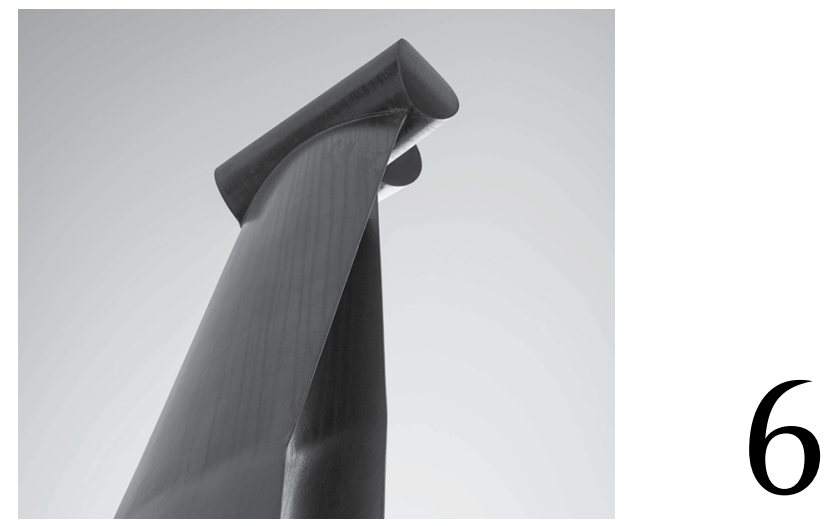

\title{
THE EFFECTS OF RACISM ON THE HUMAN BODY
}

\author{
Nina G. Jablonski
}

\section{Introduction}

The Effects of Race Project sprang from the observations and realisations of many people who voiced their concern over the diverse and sinister effects of race labelling, racialism, racism, and "race-thinking" in general. Foremost amongst the descriptive phrases that arose repeatedly in early discussions, was the "everydayness of race". For people in South Africa, the United States, and many other countries, the construct of race is an established part of social reality. Race is considered normal and a natural part of the social order. In these racialised realities, constructs of otherness underlie tacit and explicit expectations of character, intelligence, motivation, and behaviour. The concept of racialism - the formal acceptance and recognition of the reality of race and races - created a frame of acceptability for a range of behaviours from the personal to the political. Racism itself followed like a shadow, because the distance between people created by the establishment of otherness made it easier to unleash suspicion, derogation, and dehumanisation. 
In this chapter, I am not seeking to explore the psychosocial and societal problems caused by race, racism, and racialism because these have been and are being addressed much more authoritatively and sagely by others. Rather, I seek to draw attention to the wide-ranging biological effects of race-thinking and racism on the human organism.

\section{The hidden scourge of race-thinking and racism}

Race-thinking and racism are associated with so many dehumanising negatives that it is hard point to one that is the point to one aspect that is the worst or most heinous. It is thus worth considering one of the less obvious - the effects on health. If I were asked what I would most like to change with regard to race and racism, it is the constellation of divers, serious, sinister, and often life-long biological, health and psychological consequences of acute and chronic stress on the human beings who are subjected to racial othering and overt racial discrimination. There are many kinds of acute and chronic stressors, and these affect individual physical and psychosocial health through many routes affecting, broadly, the circumstances of life. Many such stressors are subtle and may seem minor at the time, but their private and, often, hidden nature makes them all the more sinister and dangerous. These hidden insults are realised in adverse effects on the body and health that may be "silent" initially, but that exert their negative effects after a lifetime of accumulation. Some of these effects have the potential to span generations. Therborn (2018) has written that racism is best considered as an "existential inequality" that "affects us as persons by shaping our constitution and recognition as autonomous and integral subjects". In other words, racism diminishes or denies agency and personhood. But we must see racism now as much more than this. It is also a "vital inequality", a social construction that shapes human life courses "with respect to life expectancy, health, and mental-somatic development" (Therborn, 2018).

Racism is an institutionalised system of oppression that designates value to persons based on race or ethnicity. Racism and racial discrimination directly affect health and well-being through health disparities at multiple levels. They also indirectly affect health by affecting socioeconomic position. Institutional racism is characterised by large organisations and imposes practices that negatively affect access to health services. Personally mediated racism occurs when healthcare providers maintain preconceived notions about racial groups which then result in the provision of substandard healthcare to racial minorities. Lastly, internalised racism involves the embodiment and acceptance of stigmatising messages by individuals in racially oppressed groups from society (Prather, Fuller, Marshall \& Jeffries, 2016). Internalised racism may be the most pernicious and least well understood, but recent research is providing insights into how chronic stress and 
negativity affect individual health through multiple pathways, including epigenetic modification of genes that control key physiological reactions.

\section{The lasting effects of stress caused by racism}

Racism has diverse and long-lasting effects on people and, far from being transient and "merely" psychological, it can cause irreversible and permanent changes to the body. The toll on personal health and well-being taken by racism, "from crib to coffin", has been recognised for decades (Gee, Walsemann \& Brondolo, 2012). Epidemiological studies have documented that the psychological stress attendant with racism has a significant deleterious effect on the development and progression of atherosclerosis, a precursor to serious cardiovascular disease (Saban, Mathews, DeVon \& Janusek, 2014). An individual's social context, especially during childhood and adolescence, is a powerful predictor of adult health, suggesting that the origins of health disparity are rooted in one's early social environment and life experiences (Saban et al., 2014). What research in the last two decades has revealed, is that social context influences the human organism at many levels, including the genetic. The physical and social environments in which a person develops and lives, trigger a series of biological responses that act on an individual's genetic blueprint (their DNA) to adjust development and lifelong programmes of bodily and mental function. In other words, human bodies and human genes are being constantly remodelled by the physical and social environment and by life experience. Far from being a passive carriage for behaviour, the body is profoundly affected by behaviours and the greater environment. The genetic programme for the body's structure and function is subject to modification by life experience and an individual's environment in the broadest sense. Of critical importance to this discussion is that the ways in which the environment may differentially integrate with genomic information are extremely varied, and that the outcomes of these interactions cannot be predetermined.

There has been much discussion in the last decade about epigenetics and its effects on human development and health. Epigenetics is the study of changes in organisms caused by modification of gene expression rather than alteration of the genetic code itself. Epigenetic changes are chemical modifications to the genome that do not alter the DNA sequence, but influence expression of the encoded genes. Epigenesis, thus, is the transmission of information to new cells during cell division that determines how genes are expressed: which genes present are "turned on" and which are silenced (Combs-Orme, 2013). Epigenetic modifications may play a profound role in translating changes in the social and behavioural environment into changes in gene expression and thence to behaviour, via a long and winding, and not predetermined, road. The field of social and behavioural epigenetics is 
focused on studying the effects of psychosocial stressors on the human phenotype (Mulligan, 2016). Many excellent reviews on social and behavioural epigenetics are available, including those written for specialists (Cunliffe, 2016; Denhardt, 2018; Notterman \& Mitchell, 2015; Vick \& Burris, 2017) and non-specialists (CombsOrme, 2013; McEwen \& Getz, 2013; Oyama \& Terry, 2016) alike.

One of the most disturbing set of discoveries emanating from research on epigenesis is that the stresses realised by an individual can affect not only the way the genes of a person work, but that some of these stress-related modifications are heritable (Szyf, Tang, Hill \& Musci, 2016; Vandegehuchte \& Janssen, 2014). When genes that control the expression of brain proteins or that modify the function of the immune system are affected by environmental (including psychosocial) stressors, the effects can be extremely serious. Epigenetic studies have the potential to elucidate the specific biological mechanisms by which social conditions become physically embodied (Needham et al., 2015). The negative biological effects of racism can be compounded over time because of the feedback loops generated by social and behaviour stressors, which induce negative emotions and accompanying biochemical and physiological changes. Behavioural functions are particularly sensitive to the programming effects of stress and nutrition during early life.

How exactly does racism affect the human body and why should it be considered an expression of vital inequality? When members of stigmatised racial populations respond to the pervasive negative racial stereotypes by accepting as true the dominant society's beliefs about their biological and/or cultural inferiority, they can internalise the racism or self-stereotyping. Internalised racism fosters the endorsement of beliefs about the innate deficiencies of one's self and one's group, and leads to lower self-esteem and psychological well-being, which in turn could adversely affect health and health behaviour in multiple ways (Williams \& Mohammed, 2013a, 2013b). Internalised racism is associated with alcohol consumption, psychological distress, being overweight, abdominal obesity, blood pressure, and fasting glucose (ibid.). Perhaps even more worrying, however, is the evidence that links social environmental conditions with changes in gene regulation, a relationship that parallels and extends the effects of the social environment on other physiological traits (Tung \& Gilad, 2013). Social status and social isolation are associated with changes in gene expression for a large number of genes. It comes as no surprise too that, because of racism, residential segregation, and structural inequality in our society, women and children suffer disproportionately from exposure to poor physical and social environments (Shields, 2017).

The most common epigenetic mechanism associated with environmental and social stress involves the methylation of DNA. DNA methylation is typically associated with gene suppression, as methyl groups that become added to DNA can 
interfere with the process of gene transcription. Alterations in DNA methylation serve as means by which risk and protective factors may affect an organism's appearance and its activity (its phenotype). DNA methylation is also increasingly being recognised as a biological process that can influence our psychological functioning from infancy to senescence (Roth, 2013). Low socioeconomic status (SES) is associated with DNA methylation several genes related to stress reactivity and inflammation. To the extent that patterns of DNA methylation influence gene expression, these findings could help explain why low SES is associated with excess morbidity and mortality (Needham et al., 2015). Although we are far from a complete understanding of the cause-and-effect role of epigenetic mechanisms in health and disease, evidence is clear that epigenetic alterations are biological consequences of environmental input throughout the life course, with early life effects being the most critical.

Epigenetic information is itself susceptible to change: its impact can be manifest as long as the environmental factor is present or can persist in its absence (Saban et al., 2014). This is extremely important as we consider the reversibility and possible transgenerational impacts of epigenetic effects. Epigenetic marks may be transmitted across generations, either directly by persisting through cell division leading to the production of eggs and sperm, or indirectly through replication in the next generation of the conditions in which the epigenetic change occurred (Rubin, 2016). New evidence indicates, however, that DNA methylation may not result in indelible epigenetic marks and that different signals arriving at intervals over a lifetime act on the genome and epigenome of the time to affect the next phase of life (Patchev, Rodrigues, Sousa, Spengler \& Almeida, 2014). Amongst the many things we don't yet know is how consistent exposure to positive, supportive environments produce a methylation pattern that places children on a positive developmental trajectory, and more resilient to subsequent adversities (Szyf et al., 2016). We are also ignorant of the mechanisms whereby DNA methylation patterns defined by early life experience are altered with childhood, adolescence, and adult experience, and how these changes relate to environmental exposures (ibid.). This information will help determine the best times for intervention, and the narrowness of the window for prevention.

\section{Epigenetic information does not mean "no hope"}

The knowledge that epigenetic research brings to light is both worrisome and elevating with respect to the long-term mitigation of the effects of racism on human well-being. It leads us, first of all, to the realisation that it is incumbent upon all governments to recognise the seriousness of the effects on human well-being of epigenetic influences, especially in early life. Findings from epigenetic studies 
should be used to promote widespread social reforms that fight the larger geographic, sociocultural, economic, and political contexts in which health disparities are embedded (Oyama \& Terry, 2016). The development of a healthy citizenry capable of making rational decisions depends upon people growing up with adequate nutrition, protected from violence and gross insecurity, and raised in environments conducive to the development of emotional security. The negative influences of racism on human health are, in many respects, similar to the negative effects of extreme poverty. With much of the world now living in highly urbanised environments in which traditional modes of nurturing individuals and policing behaviour have been eliminated, governments have a solemn responsibility to insure adequate nutrition, physical and psychosocial health care, and reduction of the threat of violence, especially against the most vulnerable members of society (children, the elderly, and women). The role of "big government" in recognising these problems and preventing their further manifestation is self-evident and must be seen as the central role of the modern state.

It has been recognised for a long time that poverty, poor nutrition, child abuse, trauma, and other adverse exposures were bad for health. What epigenetic research offers is the shedding of light on the biological pathways through which such exposures are translated into concrete, measurable increased risks of various diseases. The linkages amongst social context and epigenetics that influence the risk of cardiovascular disease, for example, have potential to support health policies aimed at the social roots of disparity in this and other disease processes. Recognition of aspects of the family and community that increase the risk of epigenetic modification may reveal aspects of the early environment that can be modified as part of community level efforts to improve well-being in those at risk (Saban et al., 2014). To the extent too that epigenetics offers a view to understand the pathways through which a mother's social disadvantage could be translated to her child's vulnerability to disease, knowledge of epigenetic mechanisms may galvanise support for public health interventions and generate new ideas for effective interventions (Shields, 2017).

The elimination of many of the health problems caused by racism does not necessarily require the eradication of racism itself, as desirable as this is, nor does it require enormous amounts of money. In this regard, Cuba stands as an example of a society in which the risk of adverse epigenetic modifications to humans has been reduced through vigilant preventive health care, conscientious antenatal care and monitoring of childhood nutrition, and reduction of the effects of acute and chronic stressors through a medical system focused on intensive personalised care provided by networks of local care givers. In Cuba, the government is also highly vigilant of any resurgence of racism because of its many recognised and ramifying adverse 
effects. Epigenetic research suggests that health promotion beginning from the prenatal period and taking an intergenerational perspective, as the Cuban system does, creates a highly propitious environment for human thriving. It also provides a useful tool for refocusing policy makers' attention back to the communities in which people live and work, and the daily quality of their lives that shape their health and those of their offspring (Shields, 2017). This novel and comprehensive approach may be the best way to help prevent health disparities from occurring and may be one of the most effective ways of reducing the multifarious negative effects of racism.

As knowledge of epigenetic processes grows, so should the capacity to develop earlylife interventions to prevent or mitigate child health disparities. Understanding how genes are differentially regulated by experience will affect how we conceptualise social inequalities and health disparities. Rather than engaging in nature versus nurture debates concerning race as a genetic or social construct, considering race as an epigenomic construct (Rubin, 2016) maybe the most accurate and appropriate perspective yet. The view in which genotype and the socially experienced world are perpetually entwined (Rubin, 2016) is the real world in which people live. 


\section{References}

Brown, W. 2018. "What Kind of World Do You Want to Live In?" Political Science Commencement, UC Berkeley, 14 May. https://bit.ly/3aPyFdI [Accessed 27 January 2020].

Combs-Orme, T. 2013. Epigenetics and the social work imperative. Social Work, 58(1). https://doi.org/10.1093/sw/sws052

Cunliffe, V.T. 2016. The epigenetic impacts of social stress: How does social adversity become biologically embedded? Epigenomics, 8(12). https://doi. org/10.2217/epi-2016-0075

Denhardt, D.T. 2018. Effect of stress on human biology: Epigenetics, adaptation, inheritance, and social significance. Journal of Cellular Physiology, 233(3). https://doi. org/10.1002/jcp.25837

Gee, G.C.; Walsemann, K.M. \& Brondolo, E. 2012. A life course perspective on how racism may be related to health inequities. American Journal of Public Health, 102(5). https://doi.org/10.2105/ AJPH.2012.300666

McEwen, B.S. \& Getz, L. 2013. Lifetime experiences, the brain and personalized medicine: An integrative perspective. Metabolism, 62(Supplement 1). https://doi. org/10.1016/j.metabol.2012.08.020

Mulligan, C.J. 2016. Early environments, stress, and the epigenetics of human health. Annual Review of Anthropology, 45(1). https://doi.org/10.1146/annurevanthro-102215-095954

Needham, B.L.; Smith, J.A.; Zhao, W.; Wang, X.; Mukherjee, B.; Kardia, S.L.R.; Shively, C.A.; Seeman, T.E.; Liu, Y. \& Diez Roux, A.V. 2015. Life course socioeconomic status and DNA methylation in genes related to stress reactivity and inflammation: The multiethnic study of atherosclerosis. Epigenetics, 10(10). https://doi.org/10.1080/1559229 4.2015.1085139

Notterman, D.A. \& Mitchell, C. 2015. Epigenetics and understanding the impact of social determinants of health. Pediatric
Clinics of North America, 62(5). https://doi. org/10.1016/j.pcl.2015.05.012

Oyama, S. \& Terry, S.F. 2016. Epigenetics and racial health inequities. Genetic Testing and Molecular Biomarkers, 20(9). https://doi. org/10.1089/gtmb.2016.29021.sjt

Patchev, A.V.; Rodrigues, A.J.; Sousa, N.; Spengler, D. \& Almeida, O.F.X. 2014. The future is now: Early life events preset adult behaviour. Acta Physiologica, 210(1). https://doi.org/10.1111/apha.12140

Prather, C.; Fuller, T.R.; Marshall, K.J. \& Jeffries, W.L. 2016. The impact of racism on the sexual and reproductive health of African American women. Journal of Women's Health, 25(7). https://doi. org/10.1089/jwh.2015.5637

Roth, T.L. 2013. Epigenetic mechanisms in the development of behavior: Advances, challenges, and future promises of a new field. Development and Psychopathology, 25(4pt2). https://doi.org/10.1017/ S0954579413000618

Rubin, L.P. 2016. Maternal and pediatric health and disease: integrating biopsychosocial models and epigenetics. Pediatric Research, 79(1-2). https://doi.org/10.1038/ pr.2015.203

Saban, K.L.; Mathews, H.L.; DeVon, H.A. \& Janusek, L.W. 2014. Epigenetics and social context: Implications for disparity in cardiovascular disease. Aging \& Disease, 5(5). https://doi.org/10.14336/ AD.2014.0500346

Shields, A.E. 2017. Epigenetic signals of how social disadvantage "gets under the skin": Achallenge to the public health community. Epigenomics, 9(3). https://doi. org/10.2217/epi-2017-0013

Szyf, M.; Tang, Y-Y.; Hill, K.G. \& Musci, R. 2016. The dynamic epigenome and its implications for behavioral interventions: a role for epigenetics to inform disorder prevention and health promotion. Translational Behavioral Medicine, 6(1). https://doi.org/10.1007/s13142-016$0387-7$ 
Therborn, G. 2018. Racism, existential inequality and problems of categorical equalisation: Reflections on the South African experience. In: N.G. Jablonski \& G. Maré (eds.). The Effects of Race. Stellenbosch: African Sun Media.

Tung, J. \& Gilad, Y. 2013. Social environmental effects on gene regulation. Cellular and Molecular Life Sciences, 70(22). https://doi. org/10.1007/s00018-013-1357-6

Vandegehuchte, M.B. \& Janssen, C.R. 2014. Epigenetics in an ecotoxicological context. Mutation Research/Genetic Toxicology and Environmental Mutagenesis, 764-765. https://doi.org/10.1016/j. mrgentox.2013.08.008
Vick, A.D. \& Burris, H.H. 2017. Epigenetics and health disparities. Current Epidemiology Reports, 4(1). https://doi. org/10.1007/s40471-017-0096-x

Williams, D.R. \& Mohammed, S.A. 2013a. Racism and health I: Pathways and scientific evidence. American Behavioral Scientist, 57(8). https://doi. org/10.1177/0002764213487340

Williams, D.R. \& Mohammed, S.A. 2013b. Racism and health II: A needed research agenda for effective interventions. American Behavioral Scientist, 57(8). https://doi. org/10.1177/0002764213487341 


\section{JPPR@SS VOLUMES IN THE SERIES}
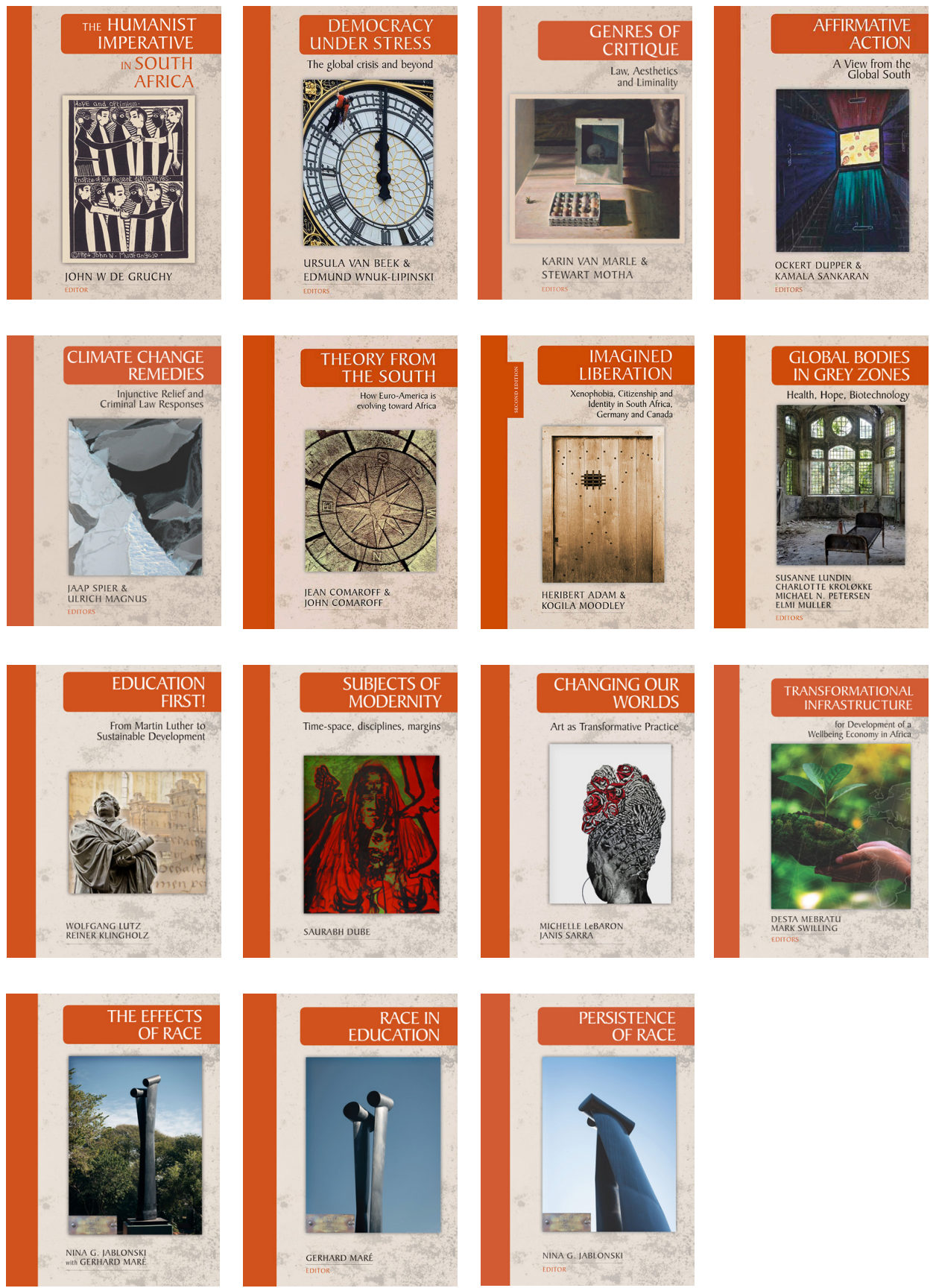